\title{
Article
}

\section{How Golden is Silence? Teaching Undergraduates the Power and Limits of RNA Interference}

\author{
Natalie H. Kuldell
}

Biological Engineering Division, Massachusetts Institute of Technology, Cambridge, MA 02139

Submitted November 14, 2005; Revised January 9, 2006; Accepted January 17, 2006

Monitoring Editor: Marshall Sundberg

\begin{abstract}
It is hard and getting harder to strike a satisfying balance in teaching. Time dedicated to student-generated models or ideas is often sacrificed in an effort to "get through the syllabus." I describe a series of RNA interference (RNAi) experiments for undergraduate students that simultaneously explores fundamental concepts in gene regulation, develops cutting-edge laboratory skills, and embraces student-directed learning. Students design a small interfering RNA (siRNA) against luciferase, add it to cells expressing this gene, and then quantitatively assess the siRNA's effect on both intended and unintended targets, using a luciferase assay and a DNA microarray. Because both RNAi and microarray technologies are relatively new, with no clear consensus on their analysis or limitations, students are encouraged to explore different approaches to the design of their reagents and interpretations of their data. The ability to creatively formulate a hypothesis-driven experimental approach to a scientific question and to critically evaluate collected data is stressed. Equally important, this experiment emphasizes how modern scientific ideas emerge, are debated, tested, and decided.
\end{abstract}

\section{INTRODUCTION}

RNA interference (RNAi) is one of the most surprising and powerful breakthroughs in recent memory for manipulating gene expression (e.g., Couzin, 2002). Gene-specific post-transcriptional silencing can be achieved when a doublestranded RNA is processed within a cell to become a small interfering RNA (siRNA) that can bind its single-stranded mRNA target (reviewed in Hannon, 2003). This binding leads to mRNA destruction, inhibiting expression of the transcribed gene. The discovery of such a remarkable mechanism and its profound silencing effect was unexpected, and intense study has followed the initial descriptions in the scientific literature in 1998 (Fire et al., 1998; Que and Jorgensen, 1998). Technical advances in the synthesis and delivery options for interfering RNAs has increased the impact of this technology (Marshall and Kaiser, 2004), while a combination of genetics, molecular biology, and biochemistry has rapidly advanced the general understanding of this exciting area of gene expression research.

Advances in RNAi coincide with genome-wide data collection from large-scale sequencing projects and from DNA

DOI: $10.1187 /$ cbe. $05-11-0124$

Address correspondence to: Natalie H. Kuldell (nkuldell@mit.edu). microarray experiments. Sequence data are available for nearly every model organism, and sequencing technology advances daily, promising ever cheaper and faster options (Zwick, 2005). There is little doubt that these data sets inform every aspect of discovery science: illuminating questions of evolution, cell physiology, and genetic control just to name a few, despite that very little information can be gleaned from an organism's DNA content alone. Experimental tools to perturb and then study cells should be paired with computational tools that compare sequences or outcomes if an investigator is to find meaning in the strings of G's, A's, T's, and C's that are too numerous to examine by hand.

DNA microarray technology is one means of exploiting sequence information to understand the gene expression pattern of a cell as a whole (Bowtell and Sambrook, 2003). In this technique, mRNA pools are isolated from cells that have been treated distinctly. These pools are differentially labeled, usually with fluorescent dyes, and then simultaneously hybridized to a slide with DNA sequences spotted or synthesized at particular addresses on the slide's surface. By comparing the dye's signal intensities at each address, investigators can assess relative expression levels for each gene represented on the slide, more than 18,000 genes for the experiment described here. 
It seems RNAi, sequence databases, and microarray analysis could be combined to provide a powerful suite of tools (Baum and Craig, 2004), enabling rational and precise modulation of gene expression and subsequent study of the cell-wide effect of such perturbation-at least in theory. In reality, RNAi experiments are hampered by unintended consequences of the RNA treatment (Couzin, 2004; Samuel, 2004); sequence databases are not fully annotated, and microarray data sets are difficult to correlate from lab to lab (Tan et al., 2003; Marshall, 2004; Bammler et al., 2005; Allison et al., 2006). Rather than ignore or simplify these ambiguities, a series of investigational laboratory experiments was developed to allow undergraduate students to accentuate them. Originally, this series was used in a class with 23 engineering students at Massachusetts Institute of Technology (MIT, Cambridge, MA); however, this curriculum could be used in its entirety or partially in a variety of lab contexts. Admittedly, MIT has technically savvy undergraduate students, excellent lab facilities, and enviable course budgets but that combination of good fortune is not required for the adoption of this lab series in other institutions or with other student cohorts. Because the primary goals are to provide a greater understanding of the techniques involved, and the data collected and its limitations, the effectiveness of these exercises would not be diminished if some of the wet lab work is omitted and precollected data sets are used for analysis (e.g., using sample data available at http://hdl. handle.net/1721.1/30603). Fundamentally important to this series, and what sets it apart from other "how to" descriptions for teaching microarrays and bioinformatics (e.g., Altman, 1998; Campbell, 2003; Brewster et al., 2004; Bradford et al., 2005; Shachak et al., 2005), is the sense that science is an ongoing process of discovery requiring student imagination and creativity. Rather than offer a collection of established facts or cookbook directions to follow, these experiments ensure that students avoid a "hands-on but brain-off" lab experience.

\section{OVERVIEW OF RNAi/MICROARRAY EXPERIMENT}

This experiment was conducted over six class sessions, each with $1 \mathrm{~h}$ of lecture and $4 \mathrm{~h}$ of lab. Lectures were an efficient way to describe the biology and mechanics of both RNAi and DNA microarrays as well as their intellectual pitfalls (Huppi et al., 2005). Primary literature was presented during lecture to show how siRNAs work in predicted and unpredicted ways. Examples from scientific articles were used to show how siRNAs can silence unintended targets of minimal sequence homology to the intended message (so called "off-target" effects) (Jackson et al., 2003; Scacheri et al., 2004) and how they can provoke an immune response in some cells ("nonspecific" effects) (Bridge et al., 2003; Judge et al., 2005). Data were also presented to illustrate the difficulty in predicting effective siRNA sequences (Reynolds et al., 2004; Miyagishi and Taira, 2005). Students seemed shocked to learn that investigators commonly design a half dozen siRNAs with the hope of finding one truly powerful and specific agent to silence a gene of interest. Thus, RNAi was broadly presented as a powerful research tool suffering from numerous design problems ... something that, as budding engineers, they were poised to address.

Similarly, DNA microarrays were described as a remarkable but flawed technology. The number of genes that can be simultaneously queried and the microfabrication techniques involved in array production were stressed as great advances. Some technical frustrations associated with microarrays, such as differences in dye stability and incorporation, were described as were the problems encountered when comparing different array platforms (e.g., Agilent, Affymatrix, and Combimatrix) due to their dissimilar manufacturing and hybridization protocols. Probe design questions arose, requiring a short but productive foray into the world of bioinformatics; exploring the meaning of E-values provided by the BLAST program; and questions such as "How many base pairs define a unique sequence in the human genome?" Finally, data analysis ambiguities were described, dropping the jaws of many in the class who could not believe no consensus has been reached for measurements such as background subtraction or repression ratios (Zhang et al., 2005; Allison et al., 2006). Before ever handling their own arrays, students were already feeling more modest about what a completely successful experiment would look like, realizing that "to a hammer, everything looks like a nail," i.e., that microarrays might not be the best experimental approach all the time.

The immediate experimental goal of the investigation was to design an siRNA that would specifically silence expression of Renilla luciferase when a plasmid expressing that gene and the student-designed siRNA were cotransfected into a human cell line. A positive control for Renilla luciferase silencing and a transfection control of firefly luciferase were provided. An outline for each day's laboratory work is presented in Figure 1.

\section{Day 1: siRNA Design}

The first day was exclusively computer based. An hour of lecture time was dedicated to an overview of RNAi, including cellular processing events of double-stranded RNAs and the general features of siRNAs, i.e., that they are generally 21-25 base pairs, have a sense and antisense strand, and so on. Each pair of students (this course at MIT is designed for

\begin{tabular}{|l|l|}
\hline Day 1: siRNA design & $\begin{array}{l}\text { Students use web-based design tool to } \\
\text { choose Renilla luciferase siRNA }\end{array}$ \\
\hline Day 2: Lipofection & $\begin{array}{l}\text { Students transfect Hela cells with } \\
\text { luciferase expressing plasmid +/- siRNA }\end{array}$ \\
\hline $\begin{array}{c}\text { Day 3: RNA isolation } \\
\text { Luciferase assays }\end{array}$ & $\begin{array}{l}\text { Students measure luciferase activity } \\
\text { of each sample and isolate RNA from } \\
\text { their cells for microarray }\end{array}$ \\
\hline Day 4: Microarray hybridization & $\begin{array}{l}\text { Students synthesize cDNA from RNA } \\
\text { pools and hybridize to DNA microarray }\end{array}$ \\
\hline Day 5: Microarray data \\
analysis & $\begin{array}{l}\text { Students use Microsoft Excel and } \\
\text { SpotFire software to analyze signal } \\
\text { intensities, draw conclusions }\end{array}$ \\
\hline Day 6: Student presentations & $\begin{array}{l}\text { Individual Powerpoint presentations of } \\
\text { siRNA design, luciferase assays and } \\
\text { microarray data }\end{array}$ \\
\hline
\end{tabular}

Figure 1. Overview of laboratory series. Students met twice each week to complete the siRNA design, transfection, and analysis described. 
Table 1. siRNAs for Renilla luciferase knockdown

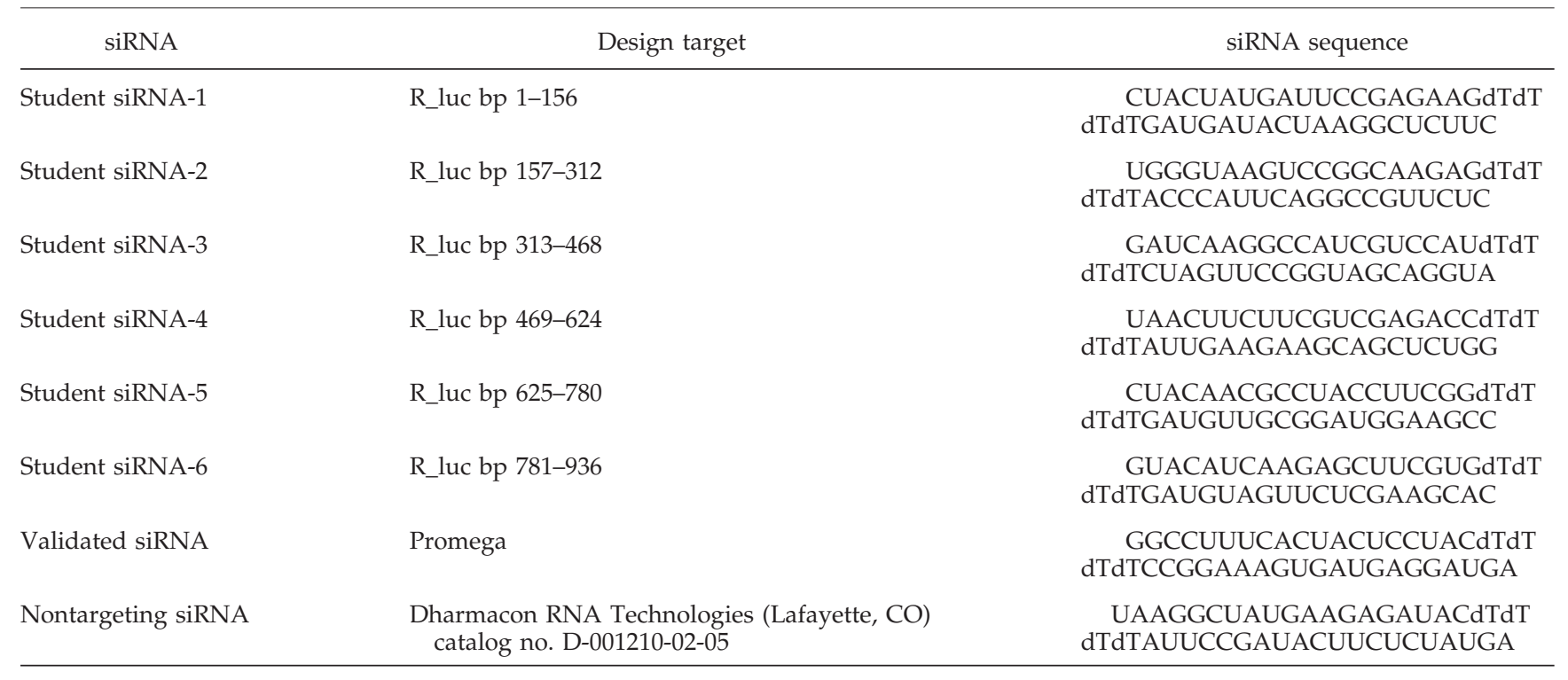

6 pairs in each of 2 classes for a total of 24 students) was assigned different portions of the Renilla luciferase gene to target. To begin, they downloaded the sequence of the entire gene from the Web and then identified their assigned portion and processed it through Ambion's (Austin, TX) siRNA design tool (http://ambion.com/techlib/misc/siRNA_ finder.html). This tool's algorithm is based on the guidelines for siRNA design originally described by Tuschl and colleagues (Elbashir et al., 2001), guidelines less stringent than some other online tools available. Students identified one sequence from their handful of candidates for synthesis. They weighed three factors to make this choice. First, they considered the G/C content of each, knowing that 30-50\% $\mathrm{G} / \mathrm{C}$ has been empirically determined to work best. Second, they considered the likelihood of secondary structure formation, examining both melting temperature and Gibbs free energy for each candidate siRNA. Third, they used Basic Local Alignment Search Tool and National Center for Biotechnology Information annotations to assess the similarity of each target sequence to expressed sequences in the human genome, favorably considering siRNA candidates with the least amount of homology. Each pair of students was able to identify a "winner" from their list of candidates (Table 1), and all their selections coincided with those made in advance by the teaching staff; therefore, siRNAs of choice were ready and waiting for students when they returned to lab to transfect them on day 2. If the tissue culture lab work described for day 2 is not feasible or if time does not permit, the experiment could continue by moving directly to day 5 where sample sets of luciferase assay and microarray data could be used to continue the experiment. Regardless, the siRNA design portion of this investigation can be extended through a homework assignment in which students are asked to reevaluate their siRNA candidates by using a different set of published guidelines (Reynolds et al., 2004). This article considers additional features of siRNAs to rank their likely efficacy. Many groups were surprised at the dramatic differences yielded by these two algorithms.

\section{Day 2: Transfection}

Students spent this day in the tissue culture facility, transfecting the siRNAs and luciferase reporter plasmid into HeLa cells (Hannon, 2003), a line derived from a cervical carcinoma that was biopsied in 1951 from a patient named Henrietta Lacks. Because this was a human cell line, the students were given significant training in the proper practices for biosafety level 2 labwork. This experiment could reasonably be expected to work with other cell lines, although no others have been tested.

The transfection pattern followed by the students is outlined in Figure 2. Two six-well plates of $50-70 \%$ confluent cells were provided for each pair. Students treated the cells with the transfection agent alone or with the reporter plasmid with and without siRNAs. The reporter plasmid (psiCHECK-2; Promega, Madison, WI) constitutively expresses both firefly and Renilla luciferase, with the former serving as control for transfection efficiency. As a positive control for RNAi, students were given a validated siRNA, previously established to decrease Renilla luciferase activity by $\sim 90 \%$. Students were also given a "nontargeting" siRNA. This commercially available reagent has no effect on Renilla luciferase expression, and, equally important, has at least four mismatches to every known human gene, giving "minimal, reproducible nonspecific target effects" according to the vendor. The validated and the nontargeting siRNAs were used as controls that would bracket the luciferase activity measurements students would make in the following lab period, giving the high and low extremes for silencing to which they could compare their siRNAs. 

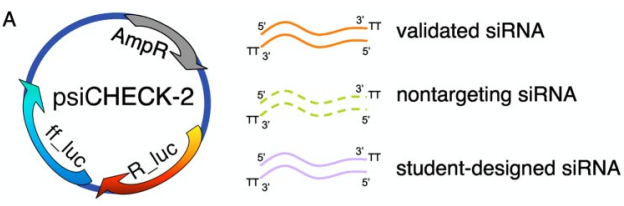

B
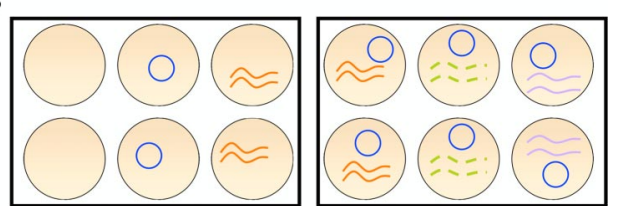

Figure 2. Transfection scheme. (A) Reagents used include psiCHECK-2 reporter vector (Promega) that constitutively expresses high levels of Renilla luciferase (R_luc) and firefly luciferase (ff_luc) as well as the ampicillin resistance gene (AmpR) for propagation in bacteria. Each pair of students also tested three siRNAs: siRNA that had been previously validated to decrease expression of R_luc, a nontargeting siRNA that has no sequence homology to any human gene, and their experimental siRNA directed against a portion of the R_luc gene. (B) Pattern for student's transfection reactions. HeLa cells grown in two six-well dishes were transfected with Lipofectamine 2K (Invitrogen, Carlsbad, CA) and, from left to right, no DNA, reporter plasmid alone, validated siRNA alone, reporter plasmid plus a validated siRNA to knockdown expression of R_luc, reporter plasmid plus a nontargeting siRNA, and finally reporter plasmid plus the student-designed siRNA. Cells were fed by the teaching staff after $24 \mathrm{~h}$, and students returned after $48 \mathrm{~h}$ to measure luciferase activity for each sample and isolate RNA.

\section{Day 3: Luciferase Assays}

The effects of siRNA treatment in mammalian cells are often most evident $48 \mathrm{~h}$ after treatment. Students returned to lab 2 days after transfection to prepare extracts from their samples and to perform luciferase assays (Figure 3) with Promega's Dual-Glo luciferase assay kit. Briefly, cells were lysed in the tissue culture dishes with a suitable buffer, an aliquot of each extract was mixed with a substrate specific for the firefly luciferase, and the light emitted over a 10 -s period was measured in a Turner TD20/20 luminometer (Turner Designs, Sunnyvale, CA). Next, each reaction tube received a second cocktail to simultaneously quench the firefly luciferase activity and initiate the reaction of Renilla luciferase. The light emitted from this second reaction was also measured for $10 \mathrm{~s}$. Students serially diluted extracts in cases when the light from either reaction exceeded instrument detection limits.

From the luciferase assay data, students made two important observations. First, they found their control reactions produced approximately $10 \times$ as many Renilla luciferase "light units" as firefly (Figure 3B, far left measurements). As a homework assignment they were asked to propose testable explanations for this difference, and several plausible ideas were put forth, including unequal expression of the two proteins as well as different luciferin/luciferase reaction efficiencies. It is not hard to imagine how their ideas could be explored and developed with future laboratory experiments. For the purposes of the experiments described here, the firefly luciferase activity served as an important control measurement, because it was expected to be unaffected by any of the treatments, thereby controlling for experimental
A

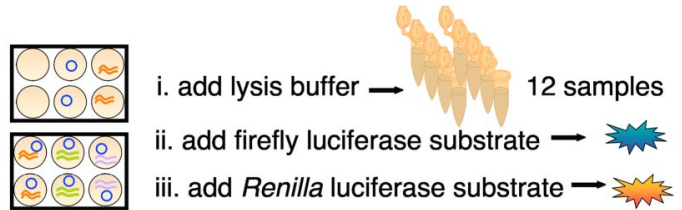

B

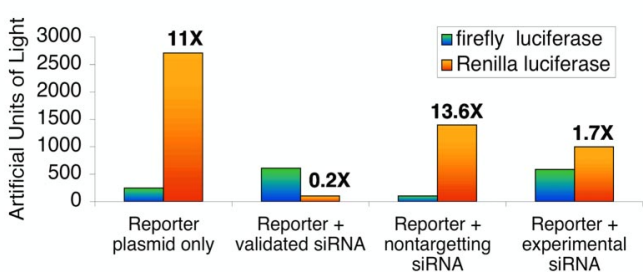

Figure 3. Luciferase assay. (A) Outline of luciferase assay protocol. Cells were lysed and each lysate was mixed with Dual-Luciferase Assay reagents (Promega). The first reagent initiates a reaction specific for firefly luciferase, and the second reagent both quenches the first reaction and initiates a reaction with Renilla luciferase. Light emitted by each reaction was measured for $10 \mathrm{~s}$ in a Turner TD20/20 luminometer. (B) Luciferase activity for selected transfected samples. From left to right, these data pairs reflect full expression of the reporter plasmid, successful knockdown of Renilla luciferase expression, the effect of transfecting a nontargeting siRNA, and the efficacy of a student-designed siRNA. Each pair represents the firefly luciferase activity in blue/green and the Renilla luciferase activity in red/orange. The ratio of Renilla to firefly luciferase activity is shown for each pair. Replicates of the indicated samples as well as no plasmid controls are not shown.

variability arising from differences in transfection efficiencies, cell lysis, lysate handling, and so on. The second important discovery was that the student-designed siRNAs were all able to silence expression of the Renilla luciferase gene (Figure 3B, far right measurements), although to different extents and rarely as effectively as the positive control. This finding generated as much relief as excitement in the class. It was nice for them to find a "winner," especially after being told how difficult such a discovery can be to achieve. The specificity of their reagent was still to be addressed, however, and they chose two extracts for further study by DNA microarray.

\section{Day 4: Microarray Hybridization}

Microarray analysis allowed the students to examine changes in HeLa cell gene expression due to off-target effects and nonspecific responses to the siRNA treatment. Students isolated total RNA from cells transfected with the reporter plasmid and their experimental siRNA. They compared the expression pattern in this sample to another sample, most often choosing a sample that had been transfected with one of the control siRNAs, reasoning that off-target effects might be identified by comparing the profile of affected genes. This comparison, however, could not reveal gene expression altered in the same way by both treatments, and some students feared they were making the "wrong" choice. Everyone eventually came to realize that microarrays are limited to pairwise comparisons and that more than two samples would be needed to answer every question of interest. For example, cells transfected with and without siRNA were required to find nonspecific effects of siRNA 


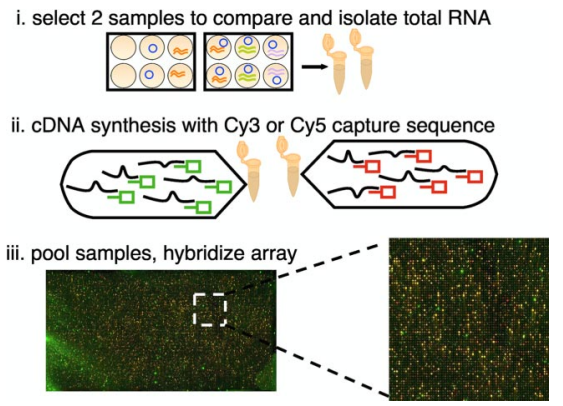

Figure 4. Microarray analysis. Students compared the gene expression pattern in two samples. For this comparison, RNA samples were isolated with the QIAGEN RNAeasy kit, and then equal masses were subjected to oligo(dT) priming and cDNA synthesis using the Genisphere kit. These oligo(dT) primers, shown as green or red boxes attached to each black RNA, contain unique capture sequences for the Genisphere fluorescent probes (Genisphere's Cy3 or Cy5 3DNA dendrimers). Students hybridized the DNA microarrays (Agilent Technologies Human v1A) with their pooled cDNA mixes, and teaching faculty followed up by washing the slides and then rehybridizing them with the fluorescent molecules. All of the microarrays gave intense and interpretable signals with this method, one example of which is shown.

treatment, but from these data it would not be evident how the expression profile differed for two siRNAs.

Students isolated total RNA from their luciferase assay extracts (diluting the lysate 1:2 with the RTL-BME lysis reagent in the QIAGEN RNA purification kit [QIAGEN, Valencia, CA] and then proceeding as directed) and performed cDNA synthesis reactions according to the instructions in the Genisphere (Hatfield, PA) 900-HS array kit (http://www.bio.davidson.edu/projects/gcat/GCATprotocols. html\#general; Figure 4). With this method, polyA-RNA is amplified with reverse transcriptase priming from oligo(dT) primers provided by the vendor. These primers contain one of two "capture sequences," each specific for a fluorescent probe. Students hybridized their cDNA pair to a single microarray, Human v1A (Agilent Technologies, Palo Alto, CA), containing 22,000 60-mer oligonucleotides (oligos) specific for 18,000 human genes. Another source for microarrays is the Genome Consortium for Active Teaching (http:/ / www.bio.davidson.edu/projects/gcat/gcat.html), a nonprofit organization whose mission is to make this technology widely available to undergraduates. The next day, the arrays were washed, reprobed with the Cy3 (green) and Cy5 (red) fluorescent labels, and then scanned. The teaching faculty performed the washing, but students could be made responsible for this step if time permits.

\section{Day 5: Microarray Data Analysis}

Students were provided with both a jpeg file of their scanned array and a 12.8-MB Microsoft Excel (Microsoft, Redmond, WA) file of 22163 rows and 88 columns with information about the identity, fluorescent intensity measurements, and quality assessment of each spot on their slide. If the wet lab work to this point is unfeasible, the students could resume here after a significant introduction to the techniques involved in the data collection by using the data available at http://hdl.handle.net/1721.1/30603. Data analysis was performed using Microsoft Excel and Spotfire Microarray Analysis software (Spotfire, Somerville, MA); however, the MAGIC Tool (Heyer et al., 2005) may have been a better choice for image analysis and clustering given its flexibility, simplicity, and open access.

To everyone, the data collected from the microarray seemed vast and difficult to navigate. What signal measurements should they compare? Is examining the mean or median more appropriate? What gave rise to the scratches, bubbles, and bright spots on the image? Can those artifacts be identified on the spreadsheet and corrected? Where was the oligo for luciferase? Undoubtedly, the homework and lecture information leading up to the day of data analysis was helpful, but equally clear is the observation that the students were most fully engaged when confronted by the data and aware of the intellectual challenge required to manage it. The importance of analyzing their own data cannot be overlooked as a factor in their willingness to immerse themselves wholeheartedly in the next level of intellectual challenge, but sample data could be used.

Each group began by trimming their data sheets to include only probe identity information and their associated Cy3 and Cy5 signal and background intensity measurements, comparing the mean and the medians of each to decide which gave a more reliable estimate for spot intensity. With some guidance by the teaching staff, students identified and deleted unused negative and positive controls from their spreadsheets and then considered whether the Cy3 and Cy5 signals needed to be normalized. Most concluded the red and green channels were well matched, a consequence of Genisphere's indirect labeling technique, and that the array represented enough genes to expect parity in the two samples analyzed. Most groups subtracted background signal though one pair (both Electrical Engineering and Computer Science majors) first used variations in background signal to explore ideas about machine signal noise.

Students enjoyed wrestling the data into a usable form but were even more delighted as they dug into their "cleaned up" measurements to make discoveries about gene expression. They followed the convention for converting intensity measurements to $\log _{2}$ values (Campbell and Heyer, 2003) and then thoughtfully considered which $\log _{2}$ values were meaningful. Students found different ways to parse their data further in an effort to discover trends and biological responses. With the only requirement being a justifiable and thoughtful approach to present to the class at the next session, some groups considered only highly expressed genes, using an $\mathrm{M}$ versus A plot to identify the border between low and high expression (Bowtell and Sambrook, 2003). Others considered only dramatically affected genes, eliminating any that differed $<16$-fold in the two treatments. Still other students restricted their analysis to reproducible signal measurements: those genes with duplicate spots on the array. Regardless of their approach, the students were surprised then delighted by their autonomy to analyze their data.

\section{Day 6: Student Presentations}

Student understanding of the material in this series of experiments is amenable to many kinds of assessment. A formal lab report is a good choice if development of scientific writing facility is a goal. An alternative form of assess- 
ment stressing oral presentation skills was chosen for this investigation. Students were asked to present their findings as a 10-min talk. There were specific written guidelines to help them structure the talk, including the approximate time and number of PowerPoint slides they should dedicate to the introduction, data presentation, and summary. A list of "dos and don'ts" was also included, with specific guidance about format (e.g., do make every element of your slide visible to the entire room. This means 20-point font or greater), content (do say what your study contributed to the field), and presentation style (don't read lists from slides). In addition to written guidelines, ideas about the assignment were exchanged though a lively discussion enjoyed by the students and teaching faculty during class time, with students offering their impressions, some very funny, of different lecturing styles encountered at MIT. In future offerings of this class, more time will be set aside for this discussion.

Students submitted an electronic file with their presentation as well as a print copy of each slide listing the associated "talking points." These outlined the content and transitions for each slide the student intended to describe, ensuring that the talks were fully planned in advance and also providing some of the more nervous public speakers with a text if they got lost or flustered during the presentation itself. Despite the large variation in the detail and length of the talking points, they were an invaluable aid in documenting and assessing the talks and they were particularly helpful to those students less comfortable with public speaking or for whom English was not a first language.

\section{LEARNING OUTCOMES}

The educational endpoints met by this investigation can be organized into three categories: knowledge, skills, and attitude. These divisions, despite being broad and somewhat overlapping, usefully frame the description of the learning outcomes from both the student and teacher perspective.

\section{Knowledge Outcomes}

Throughout this experiment, students gain first-hand experience with powerful and new technologies for expression engineering. Some of the facts, terms, concepts, and theories it emphasizes are loss of function analysis, siRNA nomenclature/structure/processing, RNAi off-target effects and how to experimentally control for them, bioluminescent reactions and their use as a readout for gene expression, microarray technology, and data analysis. Students' selfidentified knowledge outcomes were recorded on an anonymous survey and included specifics of RNAi (e.g., RNAinduced silencing complex, dicer, antisense, and target), some greater understanding of data analysis (e.g., luciferase and microarray data analysis), or both.

Student PowerPoint presentations were evaluated with a grading rubric (Figure 5A), giving some relative measure for student understanding of the material. Although a scale of 1-5 was established, assigned scores fell only on the upper end of the scale, indicating a complete or near complete understanding of the experiment. Nearly all student presentations included a complete statement of the experimental goal, offering some version of "siRNA design, efficacy, and
A Assessment of Student Understanding

B Unprescribed Step
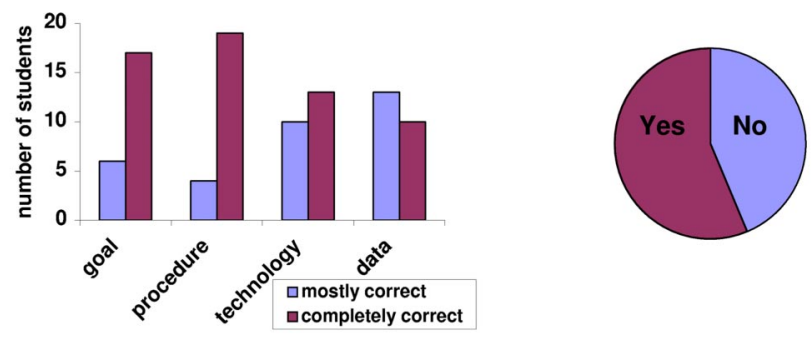

C Student Feedback

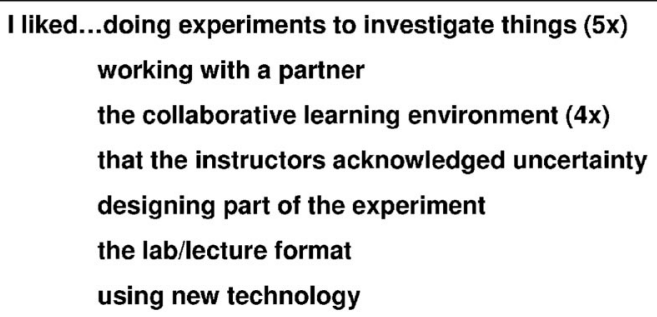

I liked...doing experiments to investigate things (5x) working with a partner

the collaborative learning environment $(4 x)$

that the instructors acknowledged uncertainty

designing part of the experiment

the lab/lecture format

using new technology

I feel confident with...my ability to do lab work (2x)

my understanding of experimental design $(2 x)$

giving presentations

Figure 5. Student learning outcomes. (A) A grading rubric was used to evaluate student understanding of the material presented and data collected. Each student presentation was evaluated for a clear statement of the experimental goal, a complete description of the experimental procedure, an accurate description of the experimental technology, and a justifiable interpretation of the data collected. A scale of 1-5 was used, where 1 is completely incorrect or missing information, 2 is mostly incorrect, 3 is equal amounts of correct and incorrect information, 4 is mostly correct, and 5 is a complete and correct presentation. (B) The sophistication of the students' data analysis was assessed by counting those who extended their explanations and findings beyond in a creative way, outside of any instruction. See text for examples. (C) A survey of open-ended questions was answered anonymously; only 10 of the classes' 23 students completed the questionnaire. Responses offered on more than one survey include the number of appearances in parentheses.

specificity" to answer the question "What did we do and why?" Most students also gave a complete and accurate description of the experimental steps, and if they omitted any steps, it was invariably those guiding their siRNA design. Most presentations included completely accurate descriptions of the experimental technology, although almost one-half of the students had small misunderstandings, for example, citing 22,000 as the number of human genes on the microarray when in fact there were approximately 18,000 gene represented, with other spots either replicates or controls. Finally, student facility with data interpretation was measured, looking particularly at their description of signals on the microarray. All students correctly described the green, red, and yellow spots as indicative of different signal ratios, but more than one-half the class did not explicitly state how the green or red signals were a consequence of upor down-regulated gene expression. This is an important 
aspect of microarray analysis, an aspect that every student should have described but only one-half did describe. Other important aspects of their data interpretation were uniformly correct, including their conclusions from the luciferase assays and transfection controls.

Students enjoyed significant autonomy throughout the investigation, and this freedom extended to their data analysis, with more than one-half of the student presentations including some unprescribed step to examine their microarray data (Figure 5B). Their approaches included sophisticated efforts at signal processing with one student devising a method for noise-reduced averaging to improve the signalto-noise ratio, and another student parsing the data along "trustworthy data points," defining those as 1.5-fold above the local background measurements. Other students took creative and ambitious paths to analyze the gene expression patterns, for example, considering gene ontology trees or looking for families of proteins that were up- and downregulated in both samples. Still other students explored fundamental limitations in the technology, for example, how local artifacts can skew signal and noise assessment and limitations of the investigation, considering how different cell types might show distinct gene expression patterns. Overall, the students showed considerable confidence and sophistication in their data analysis, reflecting a very good understanding of the experiment.

\section{Skills}

This investigation prepares students to capably and skeptically approach any gene expression experiment that includes RNAi. They obtain research-related experience that includes sensitive, hands-on work with RNA, mammalian tissue culture, enzymatic assays, and microarrays. Students gain analytical skills through their critical evaluation of experimental design and careful data analysis. Their communication skills also improve because they are obliged to keep careful records of their experimental data and to present their findings to the group. Finally, this experiment requires that students collaborate and share data, reagents, and credit for ideas, thereby building their teamwork skills. Thus, students are "learning by doing," actively engaging with the material and its challenges.

\section{Attitude}

Perhaps the most long-lasting outcome of this series of investigations is to achieve some positive change in student attitude toward themselves as investigators. Student feedback was collected to measure such change, by using a class-specific survey and the standard MIT course evaluation form, both of which the students submitted anonymously (Figure 5C). The class-specific survey asked students open-ended questions seeking their opinions about the class, about their confidence with the material, and about their recommendations to others who might want to take the class. Although responses were submitted by only 10 of the 23 enrolled students, the feedback was overwhelmingly positive. The comment that occurred most often was some version of "this lab was cool because we did real experiments instead of ones to illustrate a concept." From this sort of remark, it can be gathered that as students, they felt capable and entitled to discovery-driven learning. Another frequently expressed sentiment was some version of "I liked using new technologies," showing appreciation and excitement to be doing techniques that were the "envy of their graduate school friends."

Of the questionnaires received, nine of the 10 respondents would recommend the class to a friend, with the 10th offering no comment. The small class size and "a lab that was fun" were frequently mentioned in this regard. The experience also generated further interest in the discipline, because eight of the 10 respondents planned to take more classes in biological engineering, and the remaining respondents offered no comment or indicated some uncertainty. One student, who signed her name to the survey, wrote how the lab restored her confidence in the "drama" of biological research. Another wrote, "I feel much more interest in the future of bioengineering after the microarray experiment not really because it was so neat but more because it reveals how much more there is to be known."

\section{CONCLUSIONS}

Students who performed the series of experiments gained first-hand experience with new tools for modulating and monitoring gene expression. They were engaged and excited by the opportunity to try these "real" research techniques in an undergraduate class setting. They were further encouraged by their technical success, with all the student-designed siRNAs showing some effect on its target gene and all but one microarray giving dramatic and beautiful data. Most interesting, though, is the justifiable modesty students felt after completing this experiment, reflected in comments like "I'm glad I learned about microarrays because people always talk about them ... now I'm not so convinced that it's the most effective way to go about obtaining data because there's just so much data." Indeed, the outcomes that resonated most profoundly with the students were outcomes related to the process of discovery. Invariably, they were excited by the opportunity to design their own reagents and to try their own approach to data analysis. These left a real sense of ownership and pride in the work, which were evident to everyone when it came time to present their findings to the class.

As an educator, it is an interesting challenge to teach at the leading edge of a new field, a place where the science is still incompletely understood and the norms are not yet established. This series of experiments is an opportunity to embrace the limitations of what is known rather than be frustrated by them. Students were asked to apply their best creative and thoughtful efforts to a real problem, and, freed from the worry of being wrong, the class achieved remarkably diverse and thoughtful endpoints. This series also reinforced my belief in teaching "authentically," asking students to learn the way scientists do, in the context of an interesting question (Campbell, 2004). The experience confirmed my notion that, as a teacher, it is better to ask the right questions with the students rather than to provide all the answers. 


\section{ACKNOWLEDGMENTS}

I acknowledge the warm and collaborative environment fostered in MIT's Biological Engineering Division. In particular, I am grateful to have taught this module with Gabor Bethlendy, Rebecca Fry, and Ericka Noonan, and this class with Professors Angela Belcher, Bevin Engleward, and Leona Samson. For generously sharing reagents and for their technical assistance related to the luminescence assay, my thanks are extended to Peter Sandy and John Doench. The microarray hybridization protocol was developed with invaluable assistance from Prof. Malcolm Campbell at Davidson College and the Genome Consortium for Active Teaching. I am grateful to Steve Royce (Agilent Technologies) for providing the microarrays. I thank Tucker Crum from Wellesley College for critical reading of the manuscript and all the BE.109 students who enthusiastically and intelligently worked with this material, particularly recognizing Vivian Li for the transfection scheme shown in Figure 2 and Angelin Baskaran and Daniel Ye for the data presented in Figure 3.

\section{REFERENCES}

Allison, D. B., Cui, X., Page, G. P., and Sabripour, M. (2006). Microarray data analysis: from disarray to consolidation and consensus. Nat. Rev. Genet. 7, 55-65.

Altman, R. B. (1998). A curriculum for bioinformatics: the time is ripe. Bioinformatics 14, 549-550.

Bammler, T., et al. (2005). Standardizing global gene expression analysis between laboratories and across platforms [correction published in Nat. Methods (2005). 2, 477]. Nat. Methods 2, 351-356.

Baum, B., and Craig, G. (2004). RNAi in a postmodern, postgenomic era. Oncogene 23, 8336-8339.

Bowtell, D., and Sambrook, J. (2003). DNA Microarrays: A Molecular Cloning Manual, Cold Spring Harbor, NY: Cold Spring Harbor Laboratory Press.

Bradford, W. D., Cahoon, L., Freel, S. R., Hoopes, L.L.M., and Eckdahl, T. T. (2005). An inexpensive gel electrophoresis-based polymerase chain reaction method for quantifying mRNA levels. Cell Biol. Educ. 4, 157-168.

Brewster, J. L., Beason, K. B., Eckdahl, T. T., and Evans, I. M. (2004). The Microarray Revolution: perspectives from educators. Biochem. Mol. Biol. Educ. 32, 217-227.

Bridge, A. J., Pebernard, S., Ducraux, A., Nicoulaz, A.-L., and Iggo, R. (2003). Induction of an interferon response by RNAi vectors in mammalian cells. Nat. Genet. 34, 263-264.

Campbell, A. M., and Heyer, L. J. (2003). Discovering Genomics, Proteomics, and Bioinformatics, San Francisco: Benjamin Cummings.

Campbell, A. M. (2003) Public access for teaching genomics, proteomics, and bioinformatics. Cell Biol. Educ. 2, 98-111.

Campbell, A. M. (2004) Open access: a PLoS for education. PLoS Biol. 2, 560-563.

Couzin, J. (2002). Breakthrough of the year. Small RNAs make big splash. Science 298, 2296-2297.

Couzin, J. (2004). RNAi shows cracks in its armor. Science 306, $1124-1125$
Elbashir, S. M., Martinez, J., Patkaniowska, A., Lendeckel, W., and Tuschl, T. (2001). Functional anatomy of siRNAs for mediating efficient RNAi in Drosophila melanogaster embryo lysate. EMBO J. 20, $6877-6888$.

Fire, A., Xu, S., Montgomery, M. K., Kostas, S. A., Driver, S. E., and Mello, C. C. (1998). Potent and specific genetic interference by double-stranded RNA in Caenorhabditis elegans. Nature 391, 806811

Hannon, G. J. (2003). RNAi: A Guide to Gene Silencing, Cold Spring Harbor, NY: Cold Spring Harbor Laboratory Press.

Heyer, L. J., Moskowitz, D. Z., Abele, J. A., Karnik, P., Choi, D., Campbell, A. M., Oldham, E. E., and Akin, B. K. (2005). MAGIC Tool: integrated microarray data analysis. Bioinformatics 21, 2114 2115.

Huppi, K., Martin, S. E., and Caplen, N. J. (2005). Defining and assaying RNAi in mammalian cells. Mol. Cell 17, 1-10.

Jackson, A. L., Bartz, S. R., Schelter, J., Kobayashi, S. V., Burchard, J., Mao, M., Li, B., Cavet, G., and Linsley, P. S. (2003). Expression profiling reveals off-target gene regulation by RNAi. Nat. Biotechnol. 21, 635-637.

Judge, A. D., Sood, V., Shaw, J. R., Fang, D., McClintock, K., and MacLachlan, I. (2005). Sequence-dependent stimulation of the mammalian innate immune response by synthetic siRNA. Nat. Biotechnol. 23, 457-462.

Marshall, E. (2004). Getting the noise out of gene arrays. Science 306, 630-631.

Marshall, W. S., and Kaiser, R. J. (2004). Recent advances in the high-speed solid phase synthesis of RNA. Curr. Opin. Chem. Biol. 8, 222-229.

Miyagishi, M., and Taira, K. (2005). siRNA becomes smart and intelligent. Nat. Biotechnol. 23, 946-947.

Reynolds, A., Leake, D., Boese, Q., Scaringe, S., Marshall, W. S., and Khvorova, A. (2004). Rational siRNA design for RNA interference. Nat. Biotechnol. 22, 326-330.

Samuel, C. E. (2004). Knockdown by RNAi-proceed with caution. Nat. Biotechnol. 22, 280-282.

Scacheri, P. C., et al. (2004). Short interfering RNAs can induce unexpected and divergent changes in the levels of untargeted proteins in mammalian cells. Proc. Natl. Acad. Sci. USA 101, 1892-1897.

Shachak, A., Ophir, R., and Rubin, E. (2005) Applying instructional design theories to bioinformatics education in microarray analysis and primer design workshops. Cell Biol. Educ. 4, 199-206.

Tan, P. K., Downey, T. J., Spitznagel, E. L., Jr., Xu, P., Fu, D., Dimitrov, D. S., Lempicki, R. A., Raaka, B. M., and Cam, M. C. (2003). Evaluation of gene expression measurements from commercial microarray platforms. Nucleic Acids Res. 31, 5676-5684.

Que, Q., and Jorgensen, R. A. (1998). Homology-based control of gene expression patterns in transgenic petunia flowers. Dev. Genet. $22,100-109$.

Zhang, D., Wells, M. T., Smart C. D., and Fry W. E. (2005). Bayesian normalization and identification for differential gene expression data. J. Comput. Biol. 12, 391-406.

Zwick, M. E. (2005). Technology: a genome sequencing center in every lab. Eur. J. Hum. Genet. 13, 1167-1168. 